\title{
A Method for Assessing Influence Relationships among KPIs of Service Systems
}

\author{
Yedendra Babu Shrinivasan, Gargi Banerjee Dasgupta, Nirmit Desai, \\ and Jayan Nallacherry \\ IBM Research, Bangalore, India \\ \{yshriniv, gaargidasgupta, nirmit.desai, \\ jayan.nallacherry\}ain.ibm.com
}

\begin{abstract}
The operational performance of service systems is commonly measured with key performance indicators (KPIs), e.g., time-to-resolve, SLA compliance, and workload balance. The assumption is that healthy KPIs lead to healthy business outcomes such as customer satisfaction, cost savings, and service quality. Although the domain experts have an intuitive understanding of the causal relationships among the KPIs, the degree of influence a cause KPI has on the effect KPI is difficult to estimate based on intuition. Also, the intuitive understanding could be wrong. Further, we show how the causal relationships are intricate with aspects such as the rate of influence and conditionality in measurements. As a result, although crucial, it is nontrivial to estimate the degree of influence. Without the degree of influence, prediction of business outcomes and decisions based on them tend to be ad hoc. This paper presents a novel method for validating the intuitive direction and the polarity of a causal relationship provided by domain experts. Further, the method also estimates the degree of influence based on the measure of Pearson's correlation. Using the degree of influence and least squares regression, the method predicts values of effect KPIs. The method is evaluated by applying it on 10 widely used KPIs from 29 real-life service systems. We find that the method validates 8 of the 15 intuitive relationships and estimates the degree of influence for each of the validated relationships. Further, based on the degrees of influence and the regression model learned from the 29 service systems, the method could estimate the values of the effect KPIs with an average root-mean-squared error (RMSE) of $1.2 \%$, in 9 additional service systems.
\end{abstract}

\section{Introduction}

A Service System $(S S)$ is an organization composed of (a) the resources that support, and (b) the processes that drive service interactions so that the outcomes meet customer expectations [1 18 15]. SS are labor intensive due to the large variation in the tasks and skills of service workers (SWs) required to address service requests from multiple customers. A service provider would typically need multiple SS to support its customers. Given that the problem solving and other activities in the SS vary greatly with customers, processes are rarely supported by workflow engines and manually executed by the SWs. Hence, the KPI data availability is limited to coarse-grained and high-level measures.

Although we refer to the examples in the IT services domain, the ideas and the approach presented later apply to SS in general. To achieve service quality in the domain

C. Liu et al. (Eds.): ICSOC 2012, LNCS 7636, pp. 191-205, 2012.

(c) Springer-Verlag Berlin Heidelberg 2012 
of IT services, the service providers adopt standardized process frameworks such as ITIL 1, COBIT 2, and Lean [2] Six Sigma 3. Such frameworks also define the KPIs to enable performance assessment of each of the processes. For example, an incident management process maybe measured by the MTTR (mean time to resolve) as well as incidents resolved within SLA target time. Similarly, a work assignment process maybe measured by the mean waiting time for an incident and mean utilization of SWs. Such KPIs are widely used by service providers in making business decisions. Naturally, a poorly performing KPI attracts attention and the service provider invests in improving the underlying process.

However, the service delivery processes are inter-related in an intricate manner. For example, the KPIs of the incident management process maybe impacted by the KPIs of the work assignment process. We say that the direction of this causal relationship is from the work assignment process KPI to the incident management process KPI. Additionally, an increase in one KPI may imply a decrease in another. In such cases, We say that the polarity of the causal relationship is negative. Further, the degree of influence one KPI has on another varies - some KPIs are independent implying no influence. Lastly, the influences among KPIs do not occur instantaneously, the performance of one process influences another with a certain latency. We say that each causal relationship has a rate of influence associated with it. Sometimes, the validity of the method of measuring a KPI is conditional to assumptions about performance levels of other KPIs it is dependent on, e.g., optimal staffing level maybe computed by assuming that the work assignment process is at its best performance level and the work execution process is performing as-is on the ground. We say that the effect KPI of a causal relationship is conditional on the assumption that the performance level of the cause KPI is best, asis, or worst. These attributes of causal relationships may also evolve over time, e.g., incident management may be automated in future, making it independent of the work assignment process. Given that such changes are rare, this paper assumes that the SS are in a steady state.

In both of the above examples, an investment in the improvement of the incident management process maybe misplaced without having predicted the impact it would have on the business outcomes such as cost savings. Assessing the direction, polarity, and degree of influence among the KPIs is a prerequisite to predicting their impact to the business outcomes. As an added benefit, if the degree and rate influence of causal relationships can be assessed, a system dynamics simulation model can be created, which can answer questions such as the feasibility and cost of reaching a performance goal across multiple KPIs [11].

A possible approach is to gather KPI data to assess each of the above attributes for all pairs of KPIs to guide the decisions. However, because the KPIs involved in a relationship may come from multiple processes, inferring causality from data is difficult at best [17]. Though the domain experts can intuitively identify the cause and effect in a KPI relationship based on their knowledge of implicit temporal or data flow

\footnotetext{
${ }^{1}$ http://www.itilofficialsite.com/home/home.aspx

2 http://www.isaca.org/Knowledge-Center/cobit

3 http://asq.org/learn-about-quality/six-sigma/ overview/overview.html
} 
dependencies involved, the intuition may not hold in reality. For example, it is intuitive that SLA performance influences customer satisfaction. However, it has been shown that consistently meeting customer SLAs does not have any impact on customer satisfaction [10]. Hence, there needs to be a validation of the intuitive causal relationships and a method for estimating the degree of influence for validated relationships.

Hence, this paper (1) assumes that the intuitive direction, conditionality, and the polarity of the causal relationships among KPIs (including KPIs representing business objectives) is given by domain experts; then it proposes a method for (2) validating the direction and the polarity of a causal relationship, (3) estimating the degree of influence of a causal relationship based on a measure of correlation, and (4) predicting the values of effect KPIs for new SS by applying linear regression. We defer the assessment of the rate of influence to future work. The conditionality of a causal relationship does not need validation as it simply reflects how the KPIs are measured on the ground.

We validate this method by applying it to 3 inter-related processes and $10 \mathrm{KPIs}$ used by a large IT services provider. One of the KPIs is the business outcome of staffing deficit. Equipped with data on these KPIs from 38 real-life SS and a set of intuitive causal relationships, we apply our method to $29 \mathrm{SS}$ and find that 8 of the 15 intuitive relationships are validated and the remaining are found to be invalid. Based on the interviews of the domain experts, these results match the skepticism they expressed about the invalidated relationships and a confidence about the validated ones. Further, based on the data from the same $29 \mathrm{SS}$, we estimate the degree of influence for each of the validated relationships based on the measure of Pearson's correlation. We express the relationships as a set of linear equations and apply least squares linear regression to predict the values of effect KPIs of the remaining $9 \mathrm{SS}$. We find that the average RMSE in the estimated values is quite low at $1.2 \%$.

Business process KPIs and their influence relationships have received significant attention. In the area of SOA, it is mostly focused on measures that are collected automatically during process executions and relate to individual process instances [2120]. These data help construction of models that detect risky situations within a process instance and adapt its course towards desirable outcomes. This paper focuses on separating the process expertise from the method user by clearly defining the information that process experts provide and the results that the method user produces. This helps make the method generally applicable in the services domain. Further, we predict high-level business objectives based on coarse-grained KPIs which are not available at a process instance level and hence harder to learn from. Also, the influence relationships validated by the method are not process or SS specific and hold for any SS in the domain of IT services. Approaches to KPIs in the management science area study the influence relationships only at a conceptual level and do not lead to prediction of effect KPI values [7]616]. Also, these approaches do not consider the important notion of internal performance of KPIs.

The rest of the paper is organized as follows. Section 2 presents our general method. Section 3 describes the IT service processes, the KPIs, and the intuitive causal relationships provided by the domain experts. Section 4 describes the application of the method to the IT service KPIs and the results. We summarize the related works in Section 5 and conclude in Section 6 . 


\section{Method: Influence Estimation}

Based on KPI data from multiple SS, the goal of the method is to validate the direction and polarity of the intuitive relationships provided by the domain experts, estimate the degree of influence for the validated relationships, and construct a regression model to predict the effect KPIs for new SS. The basic measure of influence we employ is that of the Pearson's correlation coefficient 4 . Before describing the steps of our method, we introduce the notations used in the following.

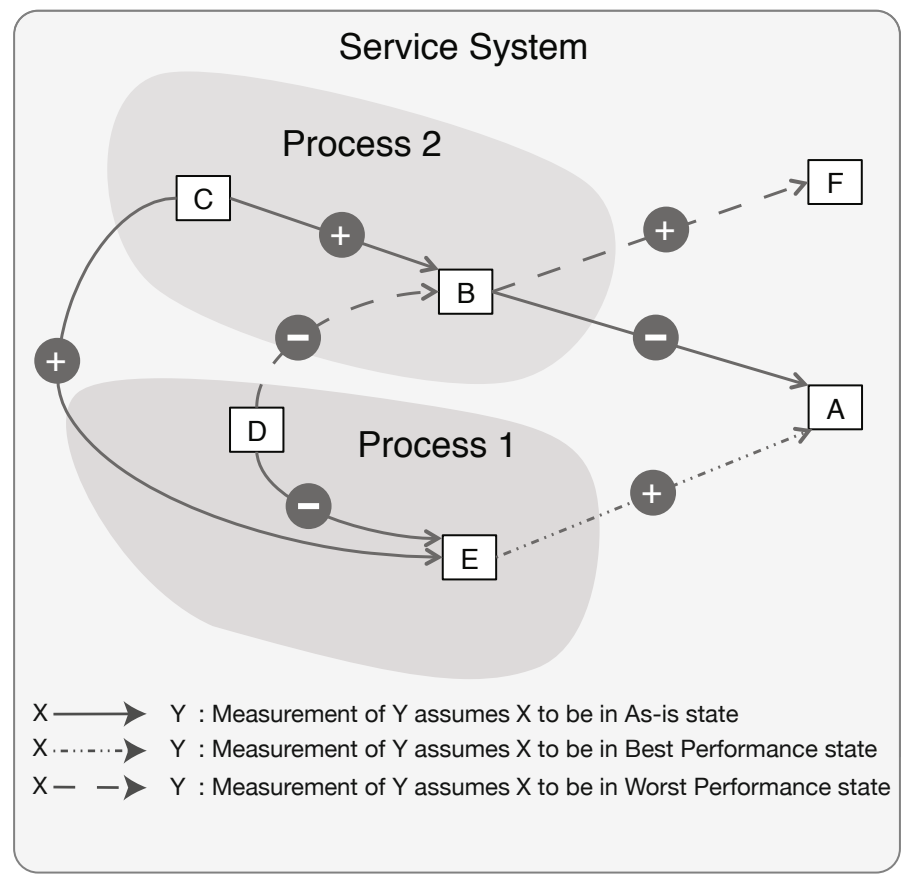

Fig. 1. Example of intuitive relationships among KPIs provided by the domain experts

Figure 1 shows an example of the relationships provided by the domain experts for a SS. KPIs $B$ and $C$ measure the performance of Process 2 whereas KPIs $D$ and $E$ measure the performance of Process $_{1}$. KPIs $A$ and $F$ measure performance of the SS as a whole and are not associated with any particular process. We call such process independent KPIs business outcomes. The direction of the edges among the KPIs indicate the direction of the causality and the signs on the edges indicate the polarity of the relationship. For example, higher the value of $C$ higher the value of $B$ whereas lower the value of $D$ higher the value of $B$. We write these as $C \stackrel{\leftrightarrows}{\rightarrow} B$ and $D \rightrightarrows B$, respectively. The conditionality of the relationships is indicated by the line type: as-is indicated by a solid line, best by a dotted line, and worst by a dashed line.

\footnotetext{
${ }^{4}$ http://en.wikipedia.org/wiki/Pearson_product-moment_ correlation_coefficient
} 


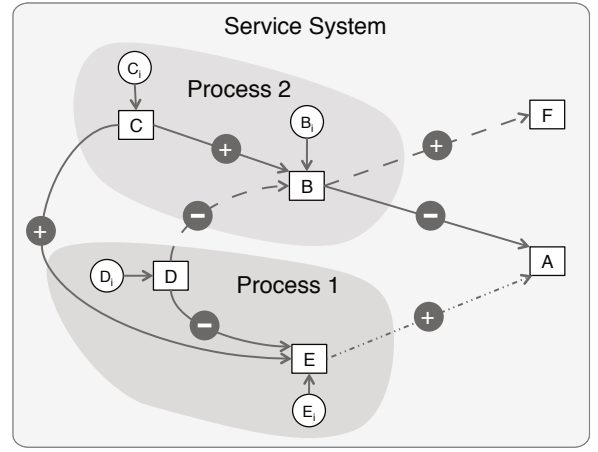

(a)

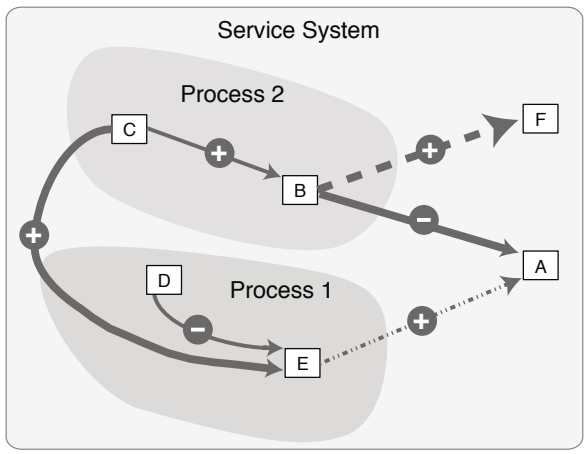

(b)

Fig. 2. (a) Influence relationships with internal performance (shown as circles) (b) Validated influence relationships among KPIs where the thickness of the edges denotes the degree of influence in relationships

\subsection{Internal and Observed KPIs}

The value of an effect KPI is not completely defined by the cause KPIs. This is because an effect KPI may have an associated process that influences the observed measurement of the KPI. For example, although a work assignment process influences the mean-time-to-resolve (MTTR), the process of problem resolution itself significantly determines the value of MTTR. Hence, we distinguish between KPIs reflecting the internal performance of the associated process alone and those reflecting the observed performance that factors in all the causal dependencies. The internal KPIs are shown as circles whereas the observed KPIs are shown as squares. For example, in Figure 2 (a), $B_{i}$ is the internal measure whereas $B$ is observed. Each observed KPI $K$ is associated with an internal KPI $K_{i}$ having a causal relationship to $K$ with a positive polarity and as-is conditionality. Note that $A$ and $F$ do not have associated internal KPIs because they are not associated with a process and are classified as business outcomes as described earlier. Intuitively, the value of observed KPI would be same as that of the internal KPI if the observed KPI were causally dependent on no other KPI. This distinction implies that an observed KPI can be expressed in terms of the associated internal KPI as well as the other observed KPIs on which the KPI is causally dependent on.

\subsection{Problem Formulation: KPI Value Prediction}

Here, we formulate the problem of predicting the value of an effect KPI via linear regression. Let $\mathcal{K}$ be the set of all KPIs in the relationships provided by the domain experts. If $\mathcal{K}_{o}$ is the set of observed KPIs and $\mathcal{K}_{i}$ is the set of internal KPIs, then $\mathcal{K}=$ $\mathcal{K}_{o} \cup \mathcal{K}_{i}$ and $\mathcal{K}_{o} \cap \mathcal{K}_{i}=\phi$. Let $\mathcal{S}$ denote the set of all SS with $\mathcal{S}_{l}$ being the set of SS in the training set and $\mathcal{S}_{t}$ being the test set, $\mathcal{S}=\mathcal{S}_{l} \cup \mathcal{S}_{t}$ and $\mathcal{S}_{l} \cap \mathcal{S}_{t}=\phi$.

Value of a KPI $K$ in SS $S_{j}$ is indicated by $S_{j}(K)$ and takes the values [0,1]. Whereas $\gamma_{K_{i} K_{j}} \in[-1,1]$ denotes the degree of influence measured by our method for the edge 
from $K_{i}$ to $K_{j}\left(K_{i}, K_{j} \in \mathcal{K}\right), \alpha_{K_{i} K_{j}} \in[-1,1]$ denotes the coefficients of regression learned from $\mathcal{S}_{l}$ for the same edge. For an observed KPI $Y \in \mathcal{K}_{o}$ that is causally dependent on KPIs $X_{1}, X_{2}, \ldots, X_{n} \in \mathcal{K}_{o}$ as well as the internal KPI $I_{Y} \in \mathcal{K}_{i}$, the linear regression model is give by Equation 11 where $\epsilon_{i}$ represents the error for $S_{i}$.

$$
S_{i}(Y)=\alpha_{I_{Y} Y} \cdot S_{i}\left(I_{Y}\right)+\alpha_{X_{1} Y} \cdot S_{i}\left(X_{1}\right)+\alpha_{X_{2} Y} \cdot S_{i}\left(X_{2}\right)+\ldots+\alpha_{X_{n} Y} \cdot S_{i}\left(X_{n}\right)+\epsilon_{i}
$$

To allow a regression solver to fit a linear curve, each of the $S_{i} \in \mathcal{S}_{l}$. Hence, the values of each of the $S_{i}(Y)$ and $S_{i}\left(X_{j}\right)(1<j<n)$ are available from the training set. However, because the values of $S_{i}\left(I_{Y}\right)$ (internal performance of $Y$ ) are not available, the coefficients cannot be fitted by a regression solver. To circumvent this issue, we apply the degree of influences to compute the $S_{i}\left(I_{Y}\right)$ as follows. Because all the values on the RHS of Equation 2 are known, we directly derive the value of $S_{i}\left(I_{y}\right)$ for all $S_{i} \in \mathcal{S}_{l}$.

$$
S_{i}\left(I_{Y}\right)=S_{i}(Y)-\gamma_{X_{1} Y} \cdot S_{i}\left(X_{1}\right)-\gamma_{X_{2} Y} \cdot S_{i}\left(X_{2}\right)-\ldots-\alpha_{X_{n} Y} \cdot S_{i}\left(X_{n}\right)
$$

The $\gamma$ terms represent the degree of influences computed via our method that is described next and show in Table 1 .

\begin{tabular}{|c|c|c|c|c|c|c|}
\hline $\begin{array}{c}\text { State of } \\
\text { cause KPI } \\
\text { assumed by } \\
\text { the effect } \\
\text { KPI }\end{array}$ & $\begin{array}{c}\text { Intuitive } \\
\text { polarity of } \\
\text { relationship } \\
(p)\end{array}$ & $\begin{array}{c}\text { Cause KPI } \\
\text { performance } \\
\text { State }\end{array}$ & $\begin{array}{l}\text { Correlation } \\
\text { between } \\
\text { cause and } \\
\text { effect KPIs }\end{array}$ & $\begin{array}{c}\text { Sign of } \\
\text { Observed } \\
\text { Correla- } \\
\text { tion }\end{array}$ & $\begin{array}{l}\text { Validation } \\
\text { test }\end{array}$ & $\begin{array}{l}\text { Degree of } \\
\text { influence }\end{array}$ \\
\hline \multirow{8}{*}{$\begin{array}{l}\text { Best perfor- } \\
\text { mance } \\
\text { state }\end{array}$} & \multirow{4}{*}{+} & \multirow{2}{*}{ Healthy } & \multirow{2}{*}{$\mathrm{a}$} & + & Valid & \multirow{8}{*}{$p \cdot \frac{(|a|+|b|)}{2}$} \\
\hline & & & & - & Invalid & \\
\hline & & \multirow{2}{*}{ Weak } & \multirow[b]{2}{*}{ b } & + & Invalid & \\
\hline & & & & - & Valid & \\
\hline & \multirow{4}{*}{ - } & \multirow{2}{*}{ Healthy } & \multirow{2}{*}{$\mathrm{a}$} & + & Invalid & \\
\hline & & & & - & Valid & \\
\hline & & \multirow{2}{*}{ Weak } & \multirow{2}{*}{ b } & + & Valid & \\
\hline & & & & - & Invalid & \\
\hline \multirow{8}{*}{$\begin{array}{l}\text { Worst per- } \\
\text { formance } \\
\text { state }\end{array}$} & \multirow{4}{*}{+} & \multirow{2}{*}{ Healthy } & \multirow{2}{*}{$\mathrm{a}$} & + & Invalid & \multirow[b]{4}{*}{$p . \frac{(|a|+|b|)}{2}$} \\
\hline & & & & - & Valid & \\
\hline & & \multirow{2}{*}{ Weak } & \multirow{2}{*}{ b } & + & Valid & \\
\hline & & & & - & Invalid & \\
\hline & \multirow{4}{*}{ - } & \multirow{2}{*}{ Healthy } & \multirow{2}{*}{$\mathrm{a}$} & + & Valid & \multirow{4}{*}{$\begin{array}{l}\text { only if } \\
\text { valid }\end{array}$} \\
\hline & & & & - & Invalid & \\
\hline & & \multirow{2}{*}{ Weak } & \multirow{2}{*}{ b } & + & Invalid & \\
\hline & & & & - & Valid & \\
\hline \multirow{4}{*}{$\begin{array}{l}\text { As-is per- } \\
\text { formance } \\
\text { state }\end{array}$} & \multirow{2}{*}{+} & \multirow{2}{*}{ All states } & \multirow{2}{*}{$\mathrm{a}$} & + & Valid & \multirow{4}{*}{$\begin{array}{c}p .|a|, \\
\text { only if } \\
\text { valid }\end{array}$} \\
\hline & & & & - & Invalid & \\
\hline & \multirow{2}{*}{-} & \multirow{2}{*}{ All states } & \multirow{2}{*}{$\mathrm{a}$} & + & Invalid & \\
\hline & & & & - & Valid & \\
\hline
\end{tabular}

Table 1. Rules for the validation of intuitive relationships and estimating the degree of influence 


\subsection{Steps}

Step $\mathbf{M}_{\mathbf{0}}$. From domain experts, gather the set of observed KPIs $\mathcal{K}_{o}$ and the direction, polarity, and conditionality of the intuitive causal relationships among them. The output of this step would look like Figure 2(a).

Step $\mathbf{M}_{1}$. Measure the values of each of the observed KPIs for a long enough period in a large enough set of SS, depending on the inherent variation and rate of change in the processes involved. Aggregate the KPIs collected over time with a suitable measure of central tendency, e.g., mean, median, or mode. The output of this step would be the value $S_{i}\left(X_{j}\right)$ for KPI $X_{j}$ and SS $S_{i}$ in $[0,1]$, where 0 indicates the best performance and 1 indicates the worst performance.

Step $\mathbf{M}_{2}$. For each cause KPI, decide the threshold of performance level such that values better than this level reflect healthy performance and values worse than this level reflect weak performance (better would be lower and worse would be higher values). Based on these thresholds, decide the performance state of the cause KPI.

Step $\mathbf{M}_{3}$. Compute the Pearson's correlation coefficient for the pair of KPIs having a causal relationship. If the conditionality is either best or worst, compute the coefficient of correlation $a$ between KPI values from SS having only healthy performance in the cause KPI and $b$ between KPI values from SS having only weak performance. This is because if the measurement of an effect KPI assumes the cause KPI to be in the best state, then for the SS where the cause KPI is in the healthy state, the cause KPI's influence would be limited. However, a positive correlation is expected because the healthier the cause KPI, the healthier the effect KPI. On the other hand, if the cause KPI is in the weak state, it has a higher negative influence on the the effect KPI.

Step $\mathbf{M}_{4}$. For each intuitive causal relationship from $M_{0}$, look up the row from Table 1 that matches the conditionality, the polarity, the performance state of cause KPI, and the sign of the correlation coefficient computed from $M_{3}$. The "Validation test" column provides the validation result of the intuitive relationship. The "Degree of influence" column provides the estimated degree of influence $\gamma_{X Y}$ for validated relationship between each KPI pair $X$ and $Y$ from $M_{0}$. The output of this Step looks like Figure 2(b).

Step $\mathbf{M}_{\mathbf{5}}$. From Equation 2, compute the estimated internal performance measure $i Y_{i}$ for each $S_{i}$ in the training set. Using these $i Y_{i}$, feed the Equation 1 to a regression solver to estimate the coefficients of regression $\alpha_{X Y}$ for the validated relationship between each KPI pair $X$ and $Y$ from $M_{4}$.

Step $\mathbf{M}_{6}$. For each $S_{i} \in \mathcal{S}_{t}$, and each effect KPI involved in a validated causal relationship, apply Equation 1 to estimate the value of the effect KPI $S_{i}(Y)$. Compute RMSE based on the difference between the estimated and the actual values.

\section{Case Study: IT Services}

This section describes the case study from the domain of IT services. In this domain, the customers own data centers and other IT infrastructures supporting their business. 
The size, complexity, and uniqueness of the technology installations drive outsourcing of the management responsibilities to specialized service providers. The service providers manage the data-centers from remote locations called delivery centers where groups of SWs skilled in specific technology areas support corresponding SRs.

Each SW has an associated skill level (discreet skill levels) and usually works on issues equal or below her skill-level. Customers submit SRs along with its associated priority. The work also arrives as internal SRs corresponding to all the internal work that goes on such as proactive fixes, preparing reports, and attending meetings. Each SR is routed to a queue manager who assesses the minimum skill-level required to service the SR. The SR is then queued up in the corresponding skill-level priority queue, where the priority may be the same as the one assigned by the customer or a modified priority based on factors such as earliest deadline or shortest service time. A resource allocator follows two alternative models: (a) as soon as an SR is queued up, it is pushed to the best SW and queued in the work queue of the SW, or (b) the SR waits in the skilllevel queue until it reaches the head of the queue and a SW with a matching skill level becomes available and pulls it.

In some cases a work assignment policy may assign work to a appropriately skilled SW, but a swing policy can overrule it by utilizing a higher skilled SW for servicing a SR with lower skill-level requirement. Typically, this is to control the growth of a lower-skill queue. A SW would service the SR by carrying out necessary work which consumes time. This time is referred to as service time with distributions that vary by the priority of a SR as well as the minimum skill-level required to service it [5]. Once a $\mathrm{SW}$ is done with an SR, it exits the system. A preemption policy may specify that a SR with higher priority preempts those with lower priority. For each customer and priority there are contractual SLA targets defined representing the SR resolution time deadlines and the percentage of the all SRs that must be resolved within this deadline within a month. For example, the contractual agreement $\left(\right.$ customer $_{1}$, High $)=\langle 4,95\rangle$, means that $95 \%$ of all SRs from customer $_{1}$ with priority=High in a month must be resolved within 4 hours. Also, the SWs work in shifts that specifies the working times as well as days. The aim is to cover the business hours of each of the customers by deploying shifts with a consummate staffing levels.

\subsection{KPIs in IT Services}

We consider three processes of work assignment, work execution, and proactive checking. Each process is further measured by several KPIS as shown in Table 2. Staffing deficit is a KPI that is a business outcome because it is measured for the entire SS and cannot be tied to any particular process. We estimate the optimal staffing, on which the measurement of staffing deficit depends, using the recently proposed and widely adopted simulation optimization framework [3|14|5]. The framework essentially minimizes the staffing requirement such that the SLA targets are met, the SR queues are not growing unbounded, and SWs do not work overtime. 


\subsection{Intuitive KPI Relationships}

The intuitive KPI relationships are shown in Figure 3. We explain the intuition behind each of the relationships in the following.

Table 2. KPIs and their measurements

\begin{tabular}{|c|c|}
\hline Work Assignment & $(1-p)$ where $p$ is: \\
\hline $\begin{array}{l}\text { A. Central Assignment: SRs should be centrally assigned } \\
\text { to SWs }\end{array}$ & $\begin{array}{l}\text { Fraction of SRs dispatched via dedi- } \\
\text { cated dispatchers. }\end{array}$ \\
\hline $\begin{array}{l}\text { B. Workload distribution: Achieve even distribution of } \\
\text { workload among SWs in each skill group. }\end{array}$ & $\begin{array}{l}\text { Proximity among utilizations of all } \\
\text { SWs of all skill groups. }\end{array}$ \\
\hline $\begin{array}{l}\text { C. Planned Up-skilling: SRs are assigned to SWs with } \\
\text { lower skills in a planned manner to up-skill them. }\end{array}$ & $\begin{array}{l}\text { Fraction of higher-skill SRs assigned } \\
\text { to lower-skilled SWs as per skill plan. }\end{array}$ \\
\hline $\begin{array}{l}\text { D. Skill Under-Utilization: SRs are assigned to SWs with } \\
\text { higher skills to control backlogs. }\end{array}$ & $\begin{array}{l}\text { Fraction of low-skill SRs assigned to } \\
\text { higher-skilled SWs. }\end{array}$ \\
\hline $\begin{array}{l}\text { E. Cross Customer work SWs should work on SRs from } \\
\text { multiple customers. }\end{array}$ & $\begin{array}{l}\text { Fraction of SWs working for multiple } \\
\text { customers. }\end{array}$ \\
\hline Work Execution & $(1-p)$ where $p$ is: \\
\hline $\begin{array}{l}\text { F. Rework: Number of attempts to required to resolve } \\
\text { SRs. }\end{array}$ & $\begin{array}{l}\text { Fraction of SRs resolved in the first at- } \\
\text { tempt. }\end{array}$ \\
\hline Proactive checking & $(1-p)$ where $p$ is: \\
\hline $\begin{array}{l}\text { G. Workload Complexity: Majority of SRs are of low } \\
\text { complexity. }\end{array}$ & $\begin{array}{l}\text { Fraction of SRs requiring the lowest } \\
\text { skill level. }\end{array}$ \\
\hline $\begin{array}{l}\text { H. Customer coverage: Proactive checking covers all } \\
\text { customers. }\end{array}$ & $\begin{array}{l}\text { Fraction of customers proactively } \\
\text { checked in the last } 60 \text { days. }\end{array}$ \\
\hline I. Issues Identified: Issues found via proactive checking. & $\begin{array}{l}1 \text { if at least one issue identified per } \\
\text { week, } 0 \text { otherwise. }\end{array}$ \\
\hline$\overline{\text { Business Outcomes }}$ & Measured as: \\
\hline J. Staffing Deficit: & $\begin{array}{l}\text { optimal staffing minus current staffing } \\
\text { divided by current staffing (optimal } \\
\text { staffing described later). }\end{array}$ \\
\hline
\end{tabular}

1. Centralized Assignment $(\mathrm{A}) \stackrel{-}{\rightarrow}$ Staffing Deficit $(\mathrm{J})$ : Lower the value of A more the work in the SS being centrally assigned. Hence, greater are the chances of it being timely assigned to the right skilled workers, which should lower the staffing requirement leading to lower current staffing. Because the measurement of $\mathbf{J}$ assumes A to be in the best state, $\mathrm{J}$ does not vary based on the actual performance in $\mathrm{A}$. Hence, the staffing deficit increases, which accounts for the negative influence.

2. Skills Underutilization (D) $\stackrel{+}{\rightarrow}$ Staffing Deficit $(\mathrm{J})$ : Higher skilled people are more expensive than their lower skilled counterparts. Higher the value of D, more the skill underutilization level, which should increase the staffing requirement. Because the measurement of $\mathbf{J}$ assumes $\mathrm{D}$ to be in the worst possible state, J does not vary based on the actual performance in D. Hence the staffing deficit increases. This accounts for the positive influence. 


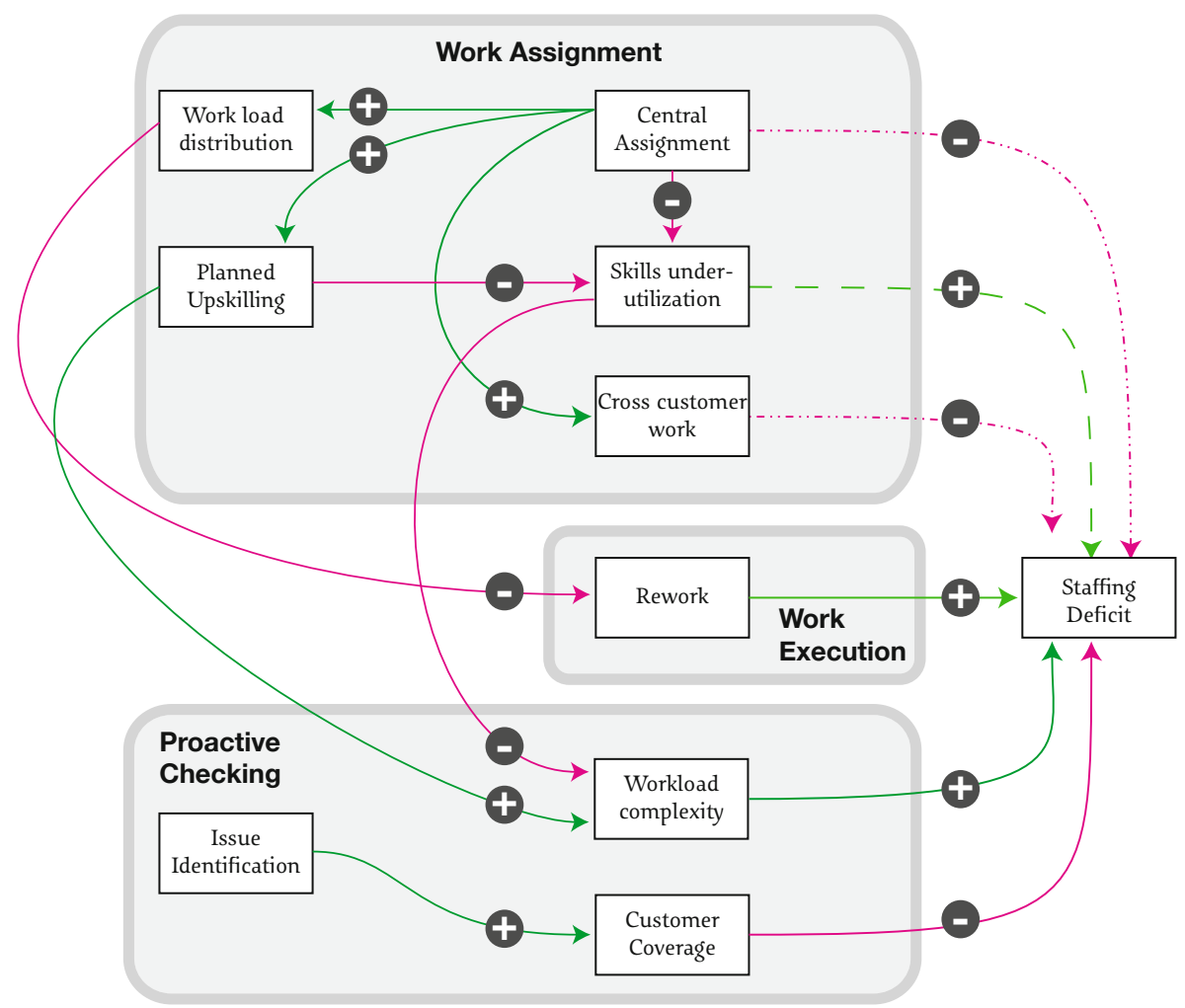

Fig. 3. Hypothetical KPIs relationship model of a SS

3. Cross Customer Work (E) $\stackrel{-}{\rightarrow}$ Staffing Deficit $(\mathrm{J})$ : Lower the value of E more workers in the SS are able to work across accounts. Hence, greater is the flexibility in work assignment which should lower the staffing requirement leading to lower current staffing. Because the measurement of $\mathrm{J}$ assumes $\mathrm{E}$ to be in the best state, $\mathrm{J}$ does not vary based on the actual performance in E. Hence, the staffing deficit increases, which accounts for the negative influence.

4. Rework $(\mathrm{F}) \stackrel{+}{\rightarrow}$ Staffing Deficit $(\mathrm{J})$ : Higher the value of F, more rework is required. Hence higher is the workload which increases the staffing requirement. Because the measurement of $\mathbf{J}$ assumes $F$ to be in the as-is state, $\mathbf{J}$ should be higher, when $\mathrm{F}$ is higher. Hence the staffing deficit increases which accounts for the positive influence.

5. Workload Complexity $(\mathrm{G}) \stackrel{+}{\rightarrow}$ Staffing Deficit $(\mathrm{J})$ : Higher the value of $\mathrm{G}$, more is the work complexity, which increases the staffing requirement. Because the measurement of $\mathbf{J}$ assumes $\mathbf{G}$ to be in the as-is state, $\mathbf{J}$ should be higher when $G$ is higher. Hence the staffing deficit increases which accounts for the positive influence.

6. Customer Coverage $(\mathrm{H}) \rightrightarrows$ Staffing Deficit $(\mathrm{J})$ : Lower the value of H, more proactive checks are triggered for customers. This translates to additional work, which increases workload and hence increases the staffing requirement. Because the 
measurement of $\mathbf{J}$ assumes $\mathrm{H}$ to be in the as-is state, $\mathbf{J}$ should be higher, when $\mathrm{H}$ is lower. Hence the staffing deficit increases which accounts for the negative influence.

7. Central Assignment $(\mathrm{A}) \stackrel{+}{\rightarrow}$ Workload Distribution (B): More the work in the SS is centrally assigned, the greater are the chances of it being distributed evenly among the workers.

8. Central Assignment $(\mathrm{A}) \stackrel{+}{\rightarrow}$ Planned Up-skilling $(\mathrm{C})$ : More the work in the SS is centrally assigned, the greater are the chances of a Up-skilling plan being followed.

9. Central Assignment $(\mathrm{A}) \stackrel{+}{\rightarrow}$ Cross-customer work $(\mathrm{E})$ : More the work in the SS is centrally assigned, the greater are the chances of it assigning multiple customers' work to a worker.

10. Central Assignment (A) $\rightarrow$ Skill under-utilization (D): More the work in the SS is centrally assigned, the lower are the chances of a high skilled worker being assigned low skilled work.

11. Skills under-utilization (D) $\rightarrow$ Workload Complexity (G): Higher the workers' skills under-utilization, lower are the chances of having repeatable less complex work in the SS.

12. Issues Identified $(\mathrm{I}) \stackrel{+}{\rightarrow}$ Customer Coverage $(\mathrm{H})$ : Higher the number of issues identified in time, greater the chances of the proactive checks being triggered for every customer.

13. Planned Up-skilling $(\mathrm{C}) \stackrel{+}{\rightarrow}$ Work Complexity $(\mathrm{G})$ : Higher the number of high skill requests assigned to low skilled workers to up-skill them, the complexity of the work in the SS becomes higher.

14. Planned Up-skilling $(C) \rightarrow$ Skills under-utilization (D): Higher the number of high skill requests assigned to low skilled workers to up-skill them, the number of high skilled workers doing low skilled work becomes lower.

15. Workload Distribution (B) $\rightarrow$ Rework (F):More evenly is the work distributed among the workers, lower are the chances that rework may be needed.

\section{Method Validation: IT Services}

We use the method proposed in Section 2 to analyze real data from a major IT services provider and validate/revisit the intuitive relationships.

We found that only 8 out of the 15 intuitive relationship hold. Table 3 provides the results of validation study and the estimated degree of influence for validated relationships based on data from 29 SS. Figure 4 shows these validated relationships along with their degree of influence. Also, the RMSE on prediction of each of the effect KPI values are shown in Table 4 with the average RMSE of $1.2 \%$. The fact that some intuitions got invalidated implies that this method is valuable. However, if an edge was missed by an expert, our method would not discover it, which is a limitation of our method. The fact that we can predict staffing deficit so accurately means that it is possible to apply this method to predict high-level business outcomes based on KPI data. 
Table 3. Influence relationship validation summary

\begin{tabular}{|c|c|c|c|c|c|c|c|c|c|}
\hline & Effect & Cause & $\begin{array}{l}\text { Assumed } \\
\text { state of } \\
\text { cause }\end{array}$ & $\begin{array}{l}\text { Intuitive } \\
\text { polarity }\end{array}$ & Population & $\begin{array}{c}\text { Expected } \\
\text { Polarity }\end{array}$ & $\begin{array}{c}\text { Observed } \\
\text { Correlation }\end{array}$ & Validation & Influence \\
\hline \multirow{2}{*}{1} & \multirow{2}{*}{ Staffing deficit } & \multirow{2}{*}{$\begin{array}{l}\text { Central } \\
\text { Assignment }\end{array}$} & \multirow{2}{*}{ Best } & \multirow{2}{*}{ - } & Healthy & - & -0.187 & Valid & \multirow{2}{*}{-0.11} \\
\hline & & & & & Weak & + & 0.034 & Valid & \\
\hline \multirow{2}{*}{2} & \multirow[b]{2}{*}{ Staffing deficit } & \multirow{2}{*}{$\begin{array}{l}\text { Cross Customer } \\
\text { Work }\end{array}$} & \multirow{2}{*}{ Best } & \multirow[b]{2}{*}{ - } & Healthy & - & 0.22 & Invalid & \\
\hline & & & & & Weak & + & -0.012 & Invalid & \\
\hline \multirow{2}{*}{3} & \multirow{2}{*}{ Staffing deficit } & \multirow{2}{*}{$\begin{array}{l}\text { Skills under- } \\
\text { utilization }\end{array}$} & \multirow{2}{*}{ Worst } & \multirow{2}{*}{+} & Healthy & - & -0.095 & Valid & \multirow{2}{*}{0.05} \\
\hline & & & & & Weak & + & -0.058 & Invalid & \\
\hline 4 & Staffing deficit & Rework & As-is & + & All & + & 0.289 & Valid & 0.29 \\
\hline 5 & Staffing deficit & $\begin{array}{l}\text { Workload } \\
\text { complexity }\end{array}$ & As-is & + & All & + & 0.053 & Valid & 0.05 \\
\hline 6 & Staffing deficit & $\begin{array}{l}\text { Customer } \\
\text { Coverage }\end{array}$ & As-is & - & All & - & -0.035 & Valid & -0.04 \\
\hline 7 & $\begin{array}{l}\text { Work load } \\
\text { distribution }\end{array}$ & $\begin{array}{c}\text { Central } \\
\text { Assignment }\end{array}$ & As-is & + & All & + & 0.931 & Valid & 0.93 \\
\hline 8 & $\begin{array}{c}\text { Planned } \\
\text { Up-skilling }\end{array}$ & $\begin{array}{c}\text { Central } \\
\text { Assignment }\end{array}$ & As-is & + & All & + & -0.243 & Invalid & \\
\hline 9 & $\begin{array}{l}\text { Skills under- } \\
\text { utilization }\end{array}$ & $\begin{array}{c}\text { Central } \\
\text { Assignment }\end{array}$ & As-is & - & All & - & 0.865 & Invalid & \\
\hline 10 & $\begin{array}{l}\text { Skills under- } \\
\text { utilization }\end{array}$ & $\begin{array}{c}\text { Planned } \\
\text { Up-skilling }\end{array}$ & As-is & - & All & - & -0.361 & Valid & -0.36 \\
\hline 11 & $\begin{array}{c}\text { Cross customer } \\
\text { work }\end{array}$ & $\begin{array}{c}\text { Central } \\
\text { Assignment }\end{array}$ & As-is & + & All & + & -0.131 & Invalid & \\
\hline 12 & Rework & $\begin{array}{l}\text { Work load } \\
\text { distribution }\end{array}$ & As-is & - & All & - & 0.761 & Invalid & \\
\hline 13 & $\begin{array}{l}\text { Workload } \\
\text { complexity }\end{array}$ & $\begin{array}{c}\text { Skills under- } \\
\text { utilization }\end{array}$ & As-is & - & All & - & 0.738 & Invalid & \\
\hline 14 & $\begin{array}{l}\text { Workload } \\
\text { complexity }\end{array}$ & $\begin{array}{c}\text { Planned } \\
\text { Up-skilling }\end{array}$ & As-is & + & All & + & -0.375 & Invalid & \\
\hline 15 & $\begin{array}{l}\text { Customer } \\
\text { Coverage }\end{array}$ & $\begin{array}{c}\text { Issue } \\
\text { Identification }\end{array}$ & As-is & + & All & + & 0.608 & Valid & 0.61 \\
\hline
\end{tabular}

\section{Related Work}

Over the last few years, industry has witnessed increased focus on attaining excellence in service systems in many verticals. Current days of service systems have been highly IT oriented and there have been studies around the need of measurement frameworks especially for IT services [9]. A fair amount of research is also focusing on service quality [16] that measures wellness of meeting the customer expectations. It has been widely discussed and adopted by delivery frameworks [7] that the operational processes and their KPIs are inter-related to each other and they influence the business outcomes of the service systems.

Human provided services especially in the areas of IT Services are highly peopleintensive and complex. Service system performance and KPIs are measured generally at a coarse-grained level rather than at process instance level and also gathering such KPI metrics is highly manual. While our work is dealing with such service systems, we found that similar studies in the areas of BPM and Service Oriented Architecture (SOA) deal with automated processes and instance level KPIs [4]. One such study [20] proposes a framework for monitoring and automatically managing dependency trees using machine learning. Further work [21] observed in this area is also about preventing KPI violations based on decision tree learning and proactive runtime adaptation. 


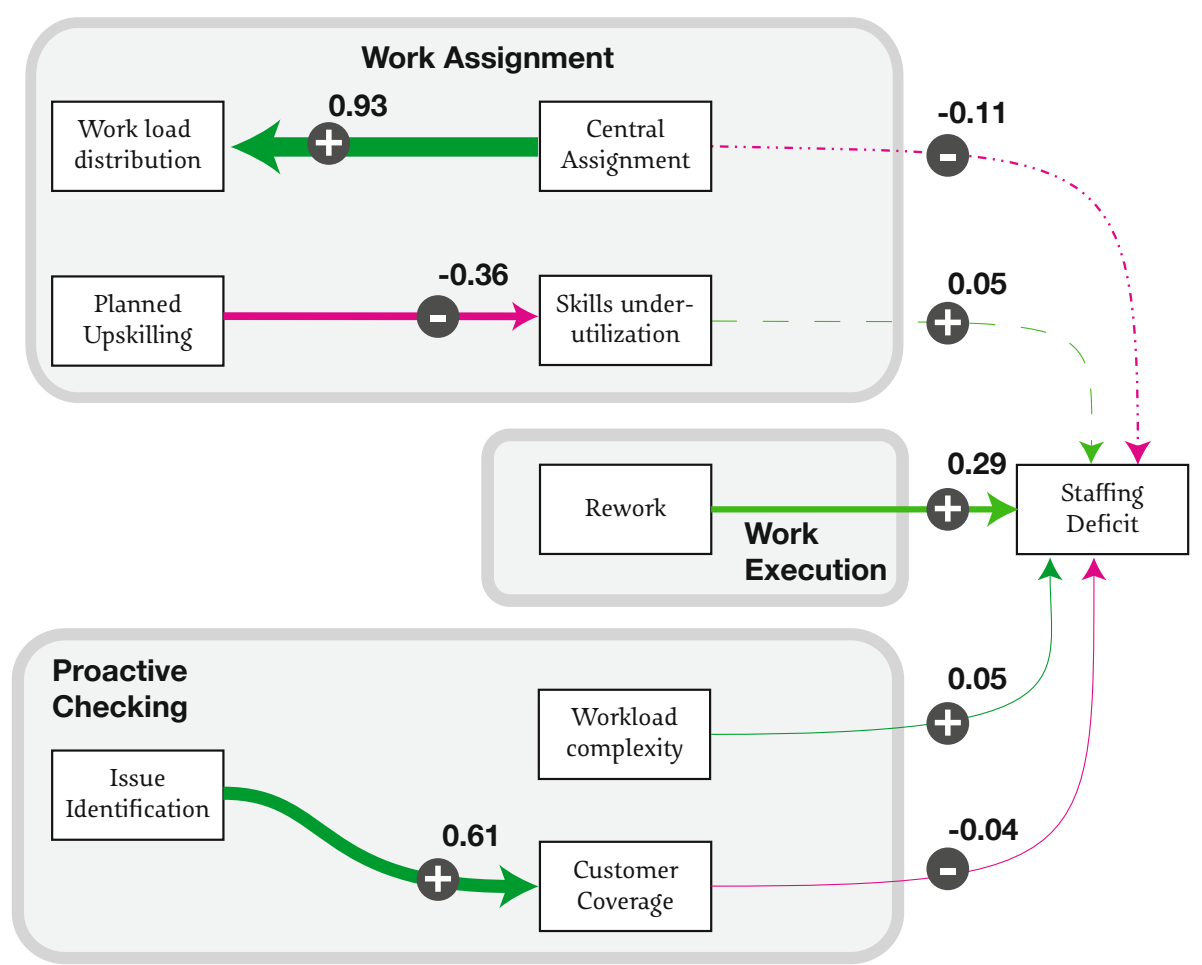

Fig. 4. Validated influence relationships among KPIs based on 29 Service Systems. The thickness of the edges denotes the degree of influence in relationships.

Additional studies in the similar area [11] use intuitive models to develop the relations of KPI and apply cognitive mapping cluster analysis. These are complementary because this paper uses real data from SS to validate such intuitive models. Other related studies [8] discuss developing intuitive models but use them for simulation to develop new processes rather than methods to validate the same with real SS. More studies exist [13 19 12], however we did not find them to be proposing a method to validate the relationships of KPIs.

The main difference between the above works and this paper is that, this paper focuses on the separating the process expertise from the application of the method for process KPI analysis. This is done by clearly defining the information that process experts provide and the results that the method users produce. This helps make the method generally applicable in the services domain because it does not assume any process insights. Further, we predict high-level business objectives based on coarse-grained KPIs which are not available at a process instance level and hence harder to learn from. Also, the influence relationships validated by the method are not process or SS specific and hold for any SS in the domain of service systems. 
Table 4. KPI prediction on 9 new SS using linear regression

\begin{tabular}{|c|c|c|c|}
\hline Effect & Cause & Regression co-efficient & RMSE \\
\hline \multirow{6}{*}{ Staffing deficit } & Central Assignment & -0.2124 & \multirow{6}{*}{0.0495} \\
\hline & Skills under- utilization & -0.0584 & \\
\hline & Rework & 0.3346 & \\
\hline & Workload complexity & -0.0259 & \\
\hline & Customer Coverage & 0.0402 & \\
\hline & Constant & -0.0288 & \\
\hline \multirow{3}{*}{ Work load distribution } & Central Assignment & 0.93 & \multirow{3}{*}{$5.487 \mathrm{E}-11$} \\
\hline & Internal Influence & & \\
\hline & Constant & $5.25616 \mathrm{E}-11$ & \\
\hline \multirow{3}{*}{ Skills under- utilization } & Planned Up-skilling & -0.36 & \multirow{3}{*}{$2.188 \mathrm{E}-10$} \\
\hline & Internal Influence & & \\
\hline & Constant & $1.04131 \mathrm{E}-10$ & \\
\hline \multirow{3}{*}{ Customer Coverage } & Issue Identification & 0.61 & \multirow{3}{*}{$2.333 \mathrm{E}-10$} \\
\hline & Internal Influence & & \\
\hline & Constant & $3.5942 \mathrm{E}-10$ & \\
\hline
\end{tabular}

\section{Conclusions}

With the aim of being able to predict the business outcomes based on KPIs alone, we presented a novel method that takes intuitive causal relationships among KPIs as an input, validates them by estimating a degree of influence based on correlation, and formulates a linear regression model based on training that can predict the business outcome. The evaluation of the method on 38 real-life SS from the IT services domain shows that the method is able to validate or invalidate the intuitive relationships as well as predict the business outcome of staffing deficit with an RMSE of only $1.2 \%$. A limitation of our method is that if a process expert missed a causal relationship, our method has no way of discovering it. However, because the prediction is based on regression, a few missing edges may simply cause a different fit in the regression and may increase the RMSE. Hence, the prediction is more robust against missing edges.

\section{References}

1. Alter, S.: Service system fundamentals: Work system, value chain, and life cycle. IBM Systems Journal 47(1), 71-85 (2008)

2. Apte, U.M., Goh, C.H.: Applying lean manufacturing principles to information intensive services (2004)

3. Banerjee, D., Dasgupta, G., Desai, N.: Simulation-based evaluation of dispatching policies in service systems. In: Winter Simulation Conference (2011)

4. Cardoso, J., Sheth, A.P., Miller, J.A., Arnold, J., Kochut, K.: Quality of service for workflows and web service processes. Journal of Web Semantics 1(3), 281-308 (2004)

5. Diao, Y., Heching, A.: Staffing optimization in complex service delivery systems. In: CNSM, pp. 1-9 (2011)

6. Elbashir, M.Z., Collier, P.A., Davern, M.J.: Measuring the effects of business intelligence systems: The relationship between business process and organizational performance. International Journal of Accounting Information Systems 9(3), 135-153 (2008) 
7. Grembergen, W.V., Haes, S.D.: Cobit's management guidelines revisited: The kgis/kpis cascade. Information Systems Control Journal 6(1), 1-3 (2005)

8. Han, K.H., Kang, J.G., Song, M.: Two-stage process analysis using the process-based performance measurement framework and business process simulation. Expert Systems with Applications 36(3, Part 2), 7080-7086 (2009)

9. Lepmets, M., Ras, E., Renault, A.: A quality measurement framework for it services by marion lepmets. In: SRII Global Conference (2011)

10. Lin, S.P., Chen, L.F., Chan, Y.H.: What is the valuable service quality gap for improving customer satisfaction? In: ICSSSM, pp. 242-247 (2009)

11. Linard, K., Fleming, C., Dvorsky, L.: System dynamics as the link between corporate vision and key performance indicators. In: System Dynamics Conference, pp. 1-13 (2002)

12. Motta, G., Pignatelli, G., Barroero, T., Longo, A.: Service level analysis method - SLAM. In: Proceedings of ICCSIT, pp. 460-466 (2010)

13. Nor, R., Nor, H., Alias, R.A., Rahman, A.A.: The ICTSQ-PM model in the context of mus: consideration of KPI and CFS. In: UTM Postgraduate Annual Research Seminar, pp. 1-5 (2008)

14. Prashanth, L.A., Prasad, H.L., Desai, N., Bhatnagar, S., Dasgupta, G.: Stochastic Optimization for Adaptive Labor Staffing in Service Systems. In: Kappel, G., Maamar, Z., MotahariNezhad, H.R. (eds.) ICSOC 2011. LNCS, vol. 7084, pp. 487-494. Springer, Heidelberg (2011)

15. Ramaswamy, L., Banavar, G.: A formal model of service delivery. In: SCC, pp. 517-520 (2008)

16. Schneider, B., White, S.S.: Service Quality: Research Perspectives (Foundations for Organizational Science). Sage Publications (2003)

17. Silverstein, C., Brin, S., Motwani, R., Ullman, J.: Scalable techniques for mining causal structures. Data Mining and Knowledge Discovery 4, 163-192 (2000)

18. Spohrer, J., Maglio, P., Bailey, J., Gruhl, D.: Steps toward a science of service systems. Computer 40(1), 71-77 (2007)

19. Strasunskas, D., Tomasgard, A.: A method to assess value of integrated operations. In: AMCIS, p. 459 (2010)

20. Wetzstein, B., Leitner, P., Rosenberg, F., Brandic, I., Dustdar, S., Leymann, F.: Monitoring and analyzing influential factors of business process performance. In: Proceedings of EDOC. IEEE Computer Society (2009)

21. Wetzstein, B., Zengin, A., Kazhamiakin, R., Marconi, A., Pistore, M., Karastoyanova, D., Leymann, F.: Preventing kpi violations in business processes based on decision tree learning and proactive runtime adaptation. Journal of Systems Integration 3(1), 3-18 (2012) 